\title{
Promoting middle school students' proportional reasoning skills through an ongoing professional development programme for teachers
}

\section{$\underline{\text { Authors, emails \& institutional affiliations }}$}

Annette Hilton ${ }^{1,2}$

(Corresponding Author)

<annette.hilton@uts.edu.au>

Geoff Hilton $^{1,2}$

<g.hilton@uq.edu.au>

Shelley Dole ${ }^{3}$

<sdole@usc.edu.au>

Merrilyn Goos ${ }^{2}$

<m.goos@uq.edu.au>

\section{Institutional affiliations}

1: $\quad$ International Research Centre for Youth Futures

University of Technology, Sydney

Ultimo, Australia 2007

2: $\quad$ School of Education

The University of Queensland

St Lucia, Australia 4072

3: $\quad$ School of Education

University of the Sunshine Coast

Sippy Downs, Australia 4556

\section{Full postal address and contact details of corresponding author:}

Annette Hilton

International Research Centre for Youth Futures

University of Technology Sydney

10.04.203, 235 Jones Street

Ultimo, Australia 2007

annette.hilton@uts.edu.au

+61 $409765264(\mathrm{M})$

+61295145377(T)

\section{Please note}

Authors \#1 and \#2 are affiliated with both listed institutions (i.e., The University of Technology Sydney and the University of Queensland);

Author \#4 is affiliated with the University of Queensland

Author \#3 is affiliated with the University of the Sunshine Coast 


\section{Promoting students' proportional reasoning skills through an ongoing professional development programme for teachers}

Proportional reasoning is mathematical reasoning involving a sense of co-variation and the ability to make multiple comparisons in relative terms (Fielding-Wells, Dole, \& Makar, 2014; Lesh, Post, \& Behr, 1988). The skills needed for proportional reasoning include multiplicative and relational thinking; a highly developed understanding of foundational concepts, including fractions, decimals, multiplication, and division; and scale (Boyer \& Levine, 2012; Lamon 2005; Lo \& Watanabe, 1997). Multiplicative thinking contrasts with additive thinking, which involves considering sums or differences between quantities (Bright, Joyner, \& Wallis, 2003). Research suggests that proportional reasoning skills do not develop naturally (Sowder et al., 1998) and many students tend to use additive thinking, find it difficult to distinguish situations of proportion from those of non-proportion, or over-rely on multiplicative thinking in situations where it is inappropriate (Van Dooren, De Bock, Hessels, Janssens, \& Verschaffel, 2005).

Proportional reasoning has been described as the cornerstone of many higher-level mathematics topics, including algebra, and the capstone of elementary school topics, such as number and measurement (Lesh et al., 1988). It is essential in many subjects beyond mathematics, including science, economics, and geography (Akatugba \& Wallace 2009; Boyer, Levine, \& Huttenlocher, 2008; Howe, Nunes, \& Bryant, 2011); is one of the most commonly used applications of mathematics in everyday life; and is essential in many professions, for example, architecture, nursing, and pharmacy. Ahl, Moore, and Dixon (1992) described proportional reasoning as a "pervasive activity that transcends topical barriers in adult life" (p. 81) and yet, Lamon (2007) estimated that close to $90 \%$ of the adult population are not proportional thinkers. The importance of developing proportional reasoning is widely recognised (Howe et al., 2011; Jones, Taylor, \& Broadwell, 2009; Staples \& Truxaw, 2012), however, its development requires a relatively long period of time (Siemon, Izard, Breed, \& 
Virgona, 2006). The National Council of Teachers of Mathematics (NCTM) (1989) argued that its development is so important that "it merits whatever time and effort that must be expended to assure its careful development" (p. 82), and yet it is rarely explicit in curriculum documents and many teachers lack sufficient pedagogical content knowledge to teach it (Kastberg,

D’Ambrosio, \& Lynch-Davis, 2012; Lobato, Orrill, Druken, \& Jacobson, 2011; Sowder et al., 1998). This is a problem because it is crucial for teachers to understand the various aspects of proportional reasoning, to employ explicit teaching strategies to promote students' proportional reasoning, and to enhance the underlying foundational concepts.

In response to these issues, an educational design study was developed to investigate the changes that occurred in teachers' knowledge and classroom practices during an ongoing professional development program and the resultant changes to students' learning outcomes. This paper focuses on the students' learning outcomes after the first year of a two-year professional development program.

\section{Theoretical Background}

Research literature abounds with examples of students' proportional reasoning difficulties. These include the inability to distinguish between proportional and non-proportional situations or to identify relationships that are multiplicative; the tendency to use additive or absolute thinking (i.e., considering a quantity by itself rather than its value in relation to other quantities) in situations of proportion that require multiplicative or relative thinking; the use of multiplicative thinking in situations requiring additive thinking; ignoring some data, such as denominators in equations; inappropriate application of algorithms, such as cross multiplication; and incorrect patterning strategies (Cramer \& Post, 1993; Lamon 1993; Lesh et al., 1988; Misailidou \& Williams, 2003; Nabors, 2003; Tourniaire \& Pulos, 1985; Van de Walle, Karp, \& Bay-Williams, 2010; Van Dooren, De Bock, \& Verschaffel, 2010). Lesh et al. (1988) described the inability to understand part-whole relationships; composite units, for example, those used in rate problems; and measurement-related difficulties as "conceptual stumbling blocks" that are 
critical to the development of primary school students' proportional reasoning (p. 9). Cortina, Visnovska, and Zuniga (2014) noted similar challenges associated with fraction-related concepts.

The difficulties experienced by students in developing proportional reasoning and its foundational concepts have been attributed to the ways in which these areas are taught. The teaching of school mathematics topics in isolation has been identified as a major problem (English \& Halford, 1995), as have school textbooks because of their treatment of related topics (e.g., fractions and ratios) as discrete and failure to adequately connect topics (Sowder et al., 1998). In addition, elementary or primary school curricula do not promote multiplicative structures, often teach multiplication and division as extensions of addition and subtraction, and fail to adequately highlight the distinctions between additive and multiplicative situations (Behr, Harel, Post, \& Lesh, 1992; Sowder et al., 1998). There have been calls for greater attention to the teaching of these areas in elementary and middle school to actively develop students' multiplicative reasoning (Lamon, 2005).

Furthermore, research has shown that teachers are not well prepared to teach the content in appropriate ways and many make the same mistakes and experience the same conceptual difficulties as their students (Lobato et al., 2011; Sowder et al., 1998). Teachers often struggle to understand the differences between additive and multiplicative situations and do not have strategies for helping their students to recognise or solve such situations. Sowder (2007) suggested that while teachers may have knowledge of mathematical algorithms and procedures, they may lack knowledge of concepts and reasoning skills. According to Thompson and Thompson (1996), even when teachers are strong in this area of understanding, they may still struggle to teach the conceptual underpinnings of multiplicative thinking to their students.

To help students develop fractional and multiplicative thinking and to prepare them for advanced concepts related to proportional reasoning, teachers need a range of knowledge and skills. These include a deep understanding of multiplicative concepts and knowledge of how to 
use multiple representations and experiences to develop such concepts; an understanding that proportional reasoning is developmental and how students develop it; the ability to distinguish between and characterise additive and multiplicative reasoning, to provide a range of contexts in which students may reason multiplicatively, and to recognise and capitalise on students' prior knowledge of multiplicative concepts; and an awareness of students' possible conceptual barriers and misconceptions (see Siebert, 2002; Taber, 2002).

Professional development is needed to assist teachers in reconceptualising the mathematics associated with multiplicative thinking and proportional reasoning (Ben-Chaim, Keret, \& Ilany, 2007; Sowder et al., 1998). Lobato et al. (2011) noted that teachers who participated in professional development on proportional reasoning were able to use more sophisticated strategies for solving proportional reasoning problems but that it is essential to focus on developing teachers' mathematical knowledge for teaching. Such knowledge is a predictor of increases in students' mathematics achievement, however, limited research has directly focused on the effects of professional development on mathematics students' learning outcomes (Goldsmith, Doerr, \& Lewis, 2014).

Watson and Beswick (2011) argued that the goal of professional development is to change teachers' beliefs and their knowledge so as to change practice, thereby enhancing student learning. Numerous models have proposed a linear pathway to represent the impact of professional development on student outcomes (e.g., Guskey, 1986; Ingvarson, Meiers, \& Beavis, 2005), however, such models have been criticised for their failure to recognise the potentially cyclic nature of the process of teacher change (Clarke \& Hollingsworth, 2002; Coenders, 2010). In contrast, Clarke and Hollingsworth (2002) suggested that teachers' learning is recursive and dynamic. Their Interconnected Model of Teacher Professional Growth (IMTPG) emphasises multiple pathways of interaction between four interconnected domains that constitute the teacher's world: the personal domain (teachers' knowledge, beliefs, and attitudes); the domain of practice (all forms of professional experimentation and preparation); 
the domain of consequence (salient outcomes, consequences perceived by the teacher); and the external domain (external sources of information or stimulus). Through the processes of reflection and enactment, change in one domain can lead to change in another. For example, changes in the external domain (e.g., through professional development programs) have the potential to impact on the other domains (i.e., teachers' knowledge, practices, and student outcomes).

The IMTPG has been used extensively in recent years as a model of teacher learning, both in the design and analysis of mathematics and science teacher professional development programs (e.g., Justi \& Van Driel, 2006; Mamlok-Naaman \& Eilks, 2011; Witterholt, Goedhart, Suhre, \& van Streun, 2012). It is consistent with our view that effective professional development can enhance students' learning outcomes through a sustained focus on enhancing teachers' knowledge and their classroom and other professional practices. The model was used, and indeed corroborated, by Goldsmith et al. (2014) who synthesised research on mathematics teachers' professional learning over the recent decades. Of the 336 coding results generated from analysis of the final 106 articles in their review, only 3\% were categorised as Student Outcomes. This finding supports other claims that there is little documented evidence on the effect of teacher professional development on student learning outcomes (Allen, Pianta, Gregory, Mikami, \& Lun, 2011; Osborne, Simon, Christodoulou, Howell-Richardson, \& Richardson, 2013; Sowder, 2007; Watson \& Beswick, 2011).

This paper reports on findings from a study that relate to this important research gap. It describes the changes in students' proportional reasoning after their teachers had engaged in the first year of a two-year professional development program. The research questions that guided this study included:

1) Does this teacher professional development program focused on targeted teaching for promoting proportional reasoning lead to improvement in students' performance?

2) If so, 
a) Which areas of proportional reasoning are enhanced?

b) Is the effect similar for students across the middle years?

\section{Method}

\section{Assessing students' proportional reasoning}

Establishing base line data about students' proportional reasoning and the difficulties they have in solving different proportional and non-proportional problems is a key first step for teachers in helping students develop better multiplicative and additive reasoning (Bright et al., 2003; Misailidou \& Williams, 2003; Van Dooren et al., 2005). Lamon (1993) described four semantic proportional reasoning problem types: rate problems in which the relationship is either commonly known or defined within the problem, scale problems, and part-part-whole relationship problems. Van Dooren et al. (2005) also identified non-proportional situations that can sometimes seem proportional to students: additive, constant, and linear. These various problem types were represented in the two-tier diagnostic instrument used in the study. Its development has been detailed elsewhere (see Hilton, Hilton, Dole, \& Goos, 2013).

Two-tier instruments provide an insight into the reasoning or conceptual understanding of students (Tan \& Treagust, 1999). There are many examples of such instruments from science education research where they are primarily used to investigate students' alternative conceptions as a basis for informing teaching strategies (see Chandrasegaran, Treagust, \& Mocerino, 2008; Halsam \& Treagust, 1987; Özmen, 2008; Tüysüz, 2009). The instrument designed for the current study consisted of 12 two-tier items. The first tier of each item was a true-false statement. The second tier of each item presented four possible reasons for the students' first tier response and students were asked to choose the most appropriate of these. The options in the second tier were based on previous research findings by members of the research team and research literature describing the common errors and reasoning types used by students in proportional and non-proportional situations. The final instrument is shown in Appendix A. An 
explanation of Question 2 from the instrument is provided here to illustrate the structure of the items used.

Question 2 requires students to use multiplicative thinking to determine the amount of flour required in a recipe when the amount of sugar is increased by $50 \%$. Response A identifies students who consider the scenario to be a constant situation. An additive thinker would be expected to select either Response B or Response D since both of these reasons consider only the additive or difference aspects of the scenario. Response $\mathrm{C}$ identifies multiplicative thinking and the recognition of the need to keep the amounts in proportion.

The items were designed to ensure consistency in problem structure. The instrument was intended for middle years students (i.e., students in Years 5 to 9 aged between 10 and 14 years), so the language used was kept as simple as possible. To ensure students who guessed an answer by selecting the first option in each tier or who didn't engage with the task were not credited with a correct response, the second tier responses were ordered so that no item had TA (Tier 1 response True, Tier 2 response A) as a correct response pair. The mathematical calculations were intentionally of low complexity in most items to allow a focus on students' application of proportional thinking, rather than complicate the question with more challenging arithmetic, however, both integer and non-integer proportional relationships were included to acknowledge the findings of Van Dooren et al. (2010) that students' reasoning can be influenced by the nature of the numbers in word problems. To prevent order effects, thereby avoiding the expectation that all items involved multiplicative thinking, the test did not begin with a proportional question. Van Dooren et al. (2005) employed a similar approach. Additionally, in some items, second tier responses were designed to determine whether students used qualitative or quantitative reasoning (see Lamon, 1993; Langrall \& Swafford, 2000; Lesh et al., 1988). The instrument was trialled through a pilot study and refined for use in the main study (see Hilton et al., 2013). 
To be credited with a correct response, students were required to answer both tiers correctly. It is important to emphasise that the items were designed to provide an insight into Year 5 to 9 students' reasoning in different situations and consequently, the instrument was not intended to be a test in the traditional sense with a 'passing grade'. The total score (out of 12) allowed $t$-tests to be used for comparison of the participant and control students' performance on the pre- and post- instruments. This approach is commonly used with two-tier tests in science education research (e.g., Özmen, 2008; Tsui \& Treagust, 2009). Analysis of the students' response combinations provided information regarding students' reasoning in each problem.

\section{The professional development program}

The professional development program was designed to incorporate the many research findings and recommendations that such learning is most effective when it

- relates to teachers' own contexts and expectations of their school environments;

- includes opportunity for teachers to identify their own learning needs and time is provided for teachers to reflect on practice;

- is collaborative and encourages collegiality among teachers and between teachers and researchers;

- focuses on students' learning needs and how to cater for them;

- is ongoing, supportive, and immerses teachers in learning activities for use in classrooms;

- focuses on curriculum implementation and makes explicit links between professional learning activities and curriculum imperatives; and

- is based on multiple sources of information.

(Hawley \& Valli, 1999; Loucks-Horsley, Stiles, Mundry, Love, \& Hewson, 2010; Luke \& McArdle, 2009; Sowder, 2007; Watson \& Beswick, 2011).

To account for the interconnected nature of teachers' professional growth, an ongoing series of professional development workshops was designed that combined theory and classroom-based activities with the goal of promoting change in teachers' knowledge and their 
classroom practices. An initial session with the teachers confirmed the need to first enhance their knowledge of proportional reasoning while focusing on their use of this knowledge in the classroom. The students' responses to the diagnostic instrument were used to inform workshop materials, to draw the teachers' attention to the learning needs of their students, and to help the teachers focus on practices that might address these needs in their classrooms.

According to Hiebert and Grouws (2007), teachers use their knowledge in the classroom for two main purposes: teaching for skill efficiency and teaching for conceptual understanding. Input from the teachers and the data from the diagnostic instrument suggested that the students were often able to employ algorithmic approaches when solving proportional situations (e.g., cross-multiplication), however, they appeared to have problems in understanding the underlying concepts. Consequently, the professional learning activities were designed to foreground the need to focus on the development of conceptual understanding.

The workshops were participant-focused. All sessions included some theoretical or content-specific presentations; however, the majority of the time was spent immersing teachers in learning activities that they could adapt and use with their students, having teachers sharing their reflections on their work at school between workshops, or in teacher-led discussions of activities and teaching approaches. Appendix B shows the program of activities in the first four workshops with associated proportional reasoning focus areas.

Because the study aimed to investigate changes in teachers' knowledge and classroom practice associated with proportional reasoning, and also focused on students' learning outcomes, a design-based research approach was adopted (Cobb, Confrey, diSessa, Lehrer, \& Schauble, 2003). This approach involves the iterative development of practical solutions (McKenney \& Reeves, 2012), which result in usable products and research insights through close interaction between researchers and participants (Reeves, McKenney, \& Herrington, 2011). An advantage of such an approach is its ability to respond to situational characteristics and account for the complex contexts of naturalistic classroom settings (Barab \& Squire, 2003; 
McKenney \& Reeves, 2012). It also aligns with the IMTPG because it acknowledges teachers' learning as recursive, involving a series of cycles of design, enactment, and evaluation; it allows research to take place in realistic school settings (the change environments in which teachers work); and provides multiple opportunities for teachers and researchers to collaborate with the goal of promoting change in knowledge, practice, and salient outcomes. The professional development program involved teachers from six school clusters in Queensland and South Australia. Each cluster consisted of one or two high schools with their geographically close primary schools. The teachers in each of the four Queensland clusters attended half-day workshops (one in each of eight 10-week terms over two years). The workshops were presented to each cluster separately. The South Australian teachers attended four full-day workshops together. Each cluster followed the same professional development program, although a focus was maintained on the characteristics of, and student needs within, individual clusters. To ensure that this focus was specific to each teacher, the student data for the pre-instrument were presented to the teachers in two ways. Firstly the data for each year level across all clusters were presented to give the teachers a sense of the trends in students' correct and erroneous reasoning and then the de-aggregated data were provided to individual teachers for their own classes.

Following each workshop, the teachers were asked to adapt workshop activities to their students' needs and prior knowledge, or to design their own activities, and trial them in their classrooms. The teachers reported the outcomes of their implementation of various activities at the next workshop. Between workshops, the research team maintained email contact with the teachers, provided support and materials online, and visited schools to support or work with the teachers as required.

\section{Administration of the diagnostic instrument}

At the beginning of the study, ethical clearance was sought from all participants. Before the professional development began, the diagnostic instrument was administered to the students in participating teachers' classes and to a number of control classes in the participating schools 
whose teachers were not directly involved in the program. To avoid the perception of the instrument as a 'traditional test', the terms pre-instrument and post-instrument are used to indicate the instruments administered at the beginning and end of the first year. The preinstrument was completed by almost 2500 students from Years 3 to 12 in Queensland and South Australia. In Queensland, the professional development program was aligned with the school year, whereas for several reasons, it did not commence until mid-year in South Australia. Consequently, only the Queensland students completed the instrument both at the start and end of the school year. Because of the rearrangement of classes and the transition of students from primary to secondary school at the end of the school year, which coincided with the end of the first year of the program, many students did not remain with the same teacher, or even in the same school, in the second year of the program. For these reasons, the data presented in this paper are only for Queensland students who completed both the pre- and post- instruments in the first year of the project. Students in year levels other than 5 to 9 completed the instrument at the request of their teachers, however, these groups have not been included because they are outside the intended target year levels of the study and in some cases the sample sizes for these year levels were quite small.

About 90 Queensland teachers and school leaders (such as principals, deputy principals, and curriculum leaders) participated in the cluster-based workshops. In total, 1026 Year 5 to 9 students in participant teachers' classes completed both the pre- and post- instruments. In addition, 277 Year 5 to 9 students in control classes completed both instruments. The instrument was administered by the classroom teachers who were briefed by the research team prior to administration to ensure all teachers followed the same procedure. The teachers received written instructions and the first page of the instrument contained written instructions for the students. The research team collected, scored, and analysed the results of the instruments. The first administration of the instrument occurred in early February, prior to any professional development and the second occurred in late November, after completion of the fourth of the 
workshops toward the end of the school year. As this instrument was not a test on which students were expected to achieve a 'passing score', the students were not told their scores on either the pre- or post- instruments to avoid them developing a perception of having passed or failed.

\section{Results}

The data were analysed on a number of levels. Firstly, the total scores obtained on the instrument by the control and participant classes in each year level were compared using $t$-tests. The response combinations of the participant students in each class were then analysed to identify areas in which students' proportional reasoning skills improved and those in which they did not.

\section{Control - participant comparison}

To establish whether there had been an effect on the students' performance after the first year of the professional development, the pre- and post- instrument scores for the control and participant classes in each year level were compared using independent $t$-tests. The data for Years 5 to 8 are shown in Table 1 . Due to attrition throughout the school year, only 15 students in the Year 9 control group completed both the pre- and post- instruments. This is of insufficient sample size to warrant inclusion here. The $t$-test data indicated no statistically significant difference between the scores for the control and participant groups in Years 5, 7, and 8 for the pre-instrument. For the Year 6 groups, the score of the participating group was significantly lower than that of the control group on the pre-instrument. The results for the post-instrument comparisons revealed statistically significant higher scores for the participant groups compared with the control classes for Years 5, 6, and 8. This is particularly interesting in the case of the Year 6 participant group, which had a significantly lower score than the control group on the pre-instrument and a significantly higher score on the post-instrument. There was no statistically significant difference between the Year 7 control and participant groups on the post-instrument. While the mean scores on the post-instrument are modest, particularly in the lower year levels, 
examination of the scores for the participant groups from Year 5 to Year 9 showed that their post-instrument scores were beyond the pre-instrument scores of students at least two years older.

Table 1.

Comparison of control and participant groups' total scores on pre- and post-instruments using t-tests

[INSERT TABLE 1 HERE]

The data in Table 1 indicate that students' proportional reasoning skills were enhanced. Having established that for the majority of year levels, there was a significant difference between the control and participant groups, a more detailed analysis was conducted to determine which areas were enhanced and whether the effects were similar across year levels.

\section{Comparison of response combinations for participant students on the pre- and post-}

\section{instruments}

Table 2 shows the percentages of students, by year level, who selected the most accurate response combination and percentages for the most common alternative response combination(s) on the pre- and post- instruments. The interpretations of the combinations are also shown. In some cases, there were qualitative reasons in the second tier. While not incorrect, we considered them less precise than the quantitative reasons.

Table 2.

Percentage of participant students selecting correct and most commonly chosen alternative response(s) 
Note: *indicates the correct response combination for the item. TA, FA, etc. denote first and second tier response combinations.

The data in Table 2 indicate that for most items, there was an increase in the percentage of participant students who chose the correct response combination from pre- to postinstrument. Generally speaking, on both instruments, there was an upward trend across year levels for correct response combinations. A graphical overview of the response patterns for selected items has been presented in Figures 1 to 6 . Although all items were analysed in further detail and are described here, the selection of the six items for more detailed analysis in this paper is based on a number of factors. Firstly, multiple items dealt with similar problem types or required similar reasoning. Secondly, the focus of some items is beyond the expected curriculum for some year levels (e.g., formal calculation of quantities in inverse proportions) and others deal with concepts not targeted in the first year of professional development (e.g., two-dimensional scale).

In each figure, the graph on the left represents the pre-instrument data and that on the right represents the post-instrument data. It is not our intention to analyse the pre-instrument data in detail as this has been done elsewhere (see Hilton et al., 2013). The focus in this paper is on the comparison of pre- and post- instrument data to describe changes in student performance after one year of the professional development program. Although the data are not continuous, they are presented as line graphs to make the trends in the data more easily seen. Van Dooren et al. (2010) also used this approach in their representation of similar data. In addition, the vertical axis on each graph, does not extend to $100 \%$ so as to make the trends more identifiable. The axes are however the same for both pre- and post- instruments to allow a fair comparison.

The data for Item 1 (additive non-proportional situation) are shown in Figure 1. The percentage of students who chose the correct response in the post-instrument was higher for all year levels than on the pre-instrument. Conversely, the percentage of students who incorrectly used multiplicative reasoning decreased slightly, except in Years 7 and 9, for whom the 
percentage remained about the same. There was a more pronounced drop in the incorrect use of multiplicative thinking in Year 8 from pre- to post- instrument, which may indicate a stronger focus by the Year 8 teachers on the distinctions between additive and multiplicative situations or it may relate to curriculum foci in that year level.

\section{[INSERT FIGURE 1 HERE]}

Figure 1. Responses for Item 1: Non-proportional additive item.

The data for the other non-proportional item (Item 7) revealed the greatest increases for Years 5 and 6. Across all year levels, the percentage of students who erroneously used multiplicative strategies decreased.

Figure 2 shows the data for Item 2, which involved the scaling-up of a recipe using multiplicative thinking. The data for both the pre- and post- instruments show that the percentage of students who incorrectly used additive thinking dropped slightly for Years 6 and 8 and to a greater extent in the case of the Year 9 students. Interestingly, more Year 7 students used additive thinking in this item than in any other year level and this percentage did not change from pre- to post- instrument. It is difficult to explain this anomalous result. It may indicate a decision on the part of some Year 7 teachers not to focus on the underlying concepts related to this item. Overall, from pre- to post- instrument, there was an increase across the year levels in the percentage of students who correctly used multiplicative thinking. The increases were greatest for Years 6, 8, and 9.

\section{[INSERT FIGURE 2 HERE]}

Figure 2. Responses for Item 2: Multiplicative thinking. 
The data in Figure 3 show that Item 3 (linear scale) was challenging for students in all year levels on the pre-instrument. There was an increase across the year levels from pre- to postinstrument in the percentage of students who correctly answered the item, with the greatest gains in Years 6 and 9. The percentage of students who incorrectly chose an absolute answer, rather than considering the scale involved, dropped significantly across the year levels, by $20 \%$ in Year 7 to over $40 \%$ in Year 9. The percentage of students who selected the qualitative response also increased from pre- to post- instrument, which suggests that these students had developed a stronger understanding of the need to consider the relative positions of the numbers on the scale but did not give the quantitative reason.

\section{[INSERT FIGURE 3 HERE]}

Figure 3. Responses for Item 3: Linear scale problem.

Item 4 dealt with a situation involving a familiar rate relationship (distance - time). As shown in Figure 4, there was an increase in the percentage of correct responses from pre- to post- instrument across all year levels, although there was a surprisingly high gain of almost $30 \%$ for Year 8 . This suggests that a strong focus by the Year 8 teachers on interpreting and using graphical representations influenced the outcome. The percentages of students who misinterpreted the graphical information remained approximately steady across the year levels from pre- to post- instrument with the exception of the Year 8 group for which the percentage dropped by about $10 \%$. In addition, the number of students who selected reasons that accurately described the graph but were not relevant decreased. This suggests that students' ability to identify relevant data had improved.

\section{[INSERT FIGURE 4 HERE]}

Figure 4. Responses for Item 4: Familiar rate problem. 
In Item 5, data were presented in tabular form and students were required to use relative thinking to respond. As shown in Figure 5, the percentage of students who answered this item correctly increased for all year levels from pre- to post- instrument, however the percentages on the post-instrument show that even in Years 8 and 9, only slightly more than $30 \%$ of students answered correctly. The strongest gains were in Years 6 and 8. While the percentage of students who incorrectly used absolute thinking decreased across all year levels, the changes were small, except in the case of Year 9 for which the decrease was approximately $14 \%$.

Similar trends were noted in Item 6, the other relative thinking question. In this case, there was a marked increase across all year levels, most pronounced in Years 8 and 9. The percentage of students who used absolute rather than relative thinking decreased across Years 5 to 8 .

[INSERT FIGURE 5 HERE]

Figure 5. Responses for Item 5: Relative thinking problem.

Figure 6 represents data for Item 8, which involved the relationship between speed and time when distance remains constant. There was a marked increase in the percentages of students who correctly selected the quantitative response from pre- to post- instrument. In all year levels, the percentage correct increased by over $15 \%$ and for Years 6 and 9 , the increase was over $20 \%$. The only commonly chosen alternative response indicated a qualitative understanding of the relationship, suggesting that the majority of students had a basic understanding of the inverse relationship between speed and time. This percentage dropped from pre- to post- instrument, most likely because some students selected the qualitative response on the pre-instrument and selected the quantitative response on the post-instrument. 


\section{[INSERT FIGURE 6 HERE]}

Figure 6. Responses for Item 8: Familiar inverse proportional situation.

Of the remaining items, for Item 9 (a missing value problem) the percentage of students answering correctly increased across the year levels and the percentage of students who answered incorrectly dropped by a corresponding amount. Although there were gains for Item 10 (inverse proportion) and Item 11 (fractional thinking and relative thinking), they were less pronounced than for other questions. There were no changes to the percentage correct for Item 12 (two-dimensional scale).

\section{Discussion}

This paper addresses the effect of teacher professional development on student learning outcomes. The research questions focused on whether students' proportional reasoning skills in particular areas were enhanced and whether effects were similar across year levels. The pre- to post- instrument data indicate that involvement in the professional development program and the resulting changes in teachers' knowledge and classroom practices enhanced participating students' proportional reasoning skills. The items were intended to allow diagnosis of what students could do in different proportional and non-proportional situations. All students, regardless of year level, were required to complete the same instrument. As such, some items would have been beyond the experience of most of the younger students. Even so, the postinstrument scores of the participant students were consistently higher than the pre-instrument scores of students two years older, which suggests that teachers' participation in professional development and subsequent targeted teaching can accelerate students' development of proportional reasoning.

There were statistically significant differences between the post-instrument scores for the control and participant classes in Years 5, 6, and 8, however, the Year 7 participants did not perform significantly better than the control students. There are several possible reasons for this. 
The most important reason is that in the schools with the control Year 7 classes, the administrators made an ongoing effort to share professional development activities with the teachers not participating in the workshops. They also placed expectations on all teachers to implement some of the ideas in their own classrooms. Consequently, the Year 7 control teachers were given information and activities from the workshops, some of which they used with their classes, which is thought to have impacted on the Year 7 control group's final score.

The second research question dealt with identifying areas of proportional reasoning that were enhanced and whether the effect was similar across the year levels. In general, there was an upward trend in the percentage of correct responses on the majority of items from lower to higher grades, which is unsurprising. Closer inspection of the data for the non-proportional items reveals that the percentage of students who erroneously used multiplicative thinking in these items decreased, particularly in the case of constant non-proportion (Item 7). The greatest increase in correct responses from pre- to post- instrument occurred for students in Years 5 and 6 in the case of the non-proportional constant question, and by a similar amount across all year levels on the non-proportional additive item (Item 1). Van Dooren et al. (2005) found that after Year 6, students become more adept at distinguishing between proportional and nonproportional situations, however, the data from the non-proportional items in the current study indicate that this skill can be promoted in students in earlier year levels.

In the items that dealt with proportional situations, the number of students who used additive or absolute thinking inappropriately decreased. There was also an increase in performance across the year levels, which was quite consistent for items that involved multiplicative thinking (Item 2), relative thinking (Item 5), and part-part-whole relationships (Item 9). In the case of one-dimensional scale (Item 3) and the familiar rate situation (Item 8), the increase was consistently high from Year 5 to Year 9. For other items, although there was an increase in the lower year levels, a greater increase occurred in the upper year levels (8 and 9). These items involved inverse proportion (Item 10), or multiple concepts, such as rate and 
relative thinking (Item 6) and fractional and relative thinking (Item 11). These latter differences reflect a greater curriculum focus on inverse proportion and rate in Years 8 and 9, providing teachers of these year levels with more opportunities to focus on such topics. The differences between younger and older students' performances also suggest that older students are more able to develop the proportional reasoning skills required in more complex situations than students in lower year levels due to factors such as differences in cognitive development, prior knowledge, or learning experiences.

For several items, the percentage of students who answered correctly on the postinstrument was still quite low; in many cases less than $50 \%$. This may be due to a number of reasons, many of which are articulated in the literature. Firstly, proportional reasoning is challenging for students (Cramer \& Post, 1993; Staples \& Truxaw, 2012) and it does not always develop naturally (Sowder et al., 1998). Consequently, sufficient time and an ongoing focus on proportional reasoning concepts and skills are necessary to promote students' proportional reasoning (NCTM, 1989; Siemon et al., 2006). For many students, there remained a tendency to use additive or multiplicative strategies inappropriately, which suggests that these students had yet to develop the skills necessary to identify proportional situations, a finding that aligns with other research (e.g., Tourniaire \& Poulos, 2003; Van Dooren et al., 2005; 2010). Secondly, some concepts may be less appropriate for students in the lower middle years whereas a greater improvement might be achieved with older students (e.g., inverse proportion). It is also possible that teachers made professional judgments related to their students' existing skills and understanding or curriculum requirements and chose not to focus on certain proportional reasoning concepts. In addition, the first year of the professional development program did not focus on all of the concepts targeted by the instrument. Some key areas, for example, twodimensional scale and inverse proportion, received greater focus in the second year of the program.

These data were obtained after only one year of a two-year professional development 
program. Research suggests that positive effects of professional development interventions generally occur when the interventions have over 30 contact hours (Guskey \& Yoon, 2009) or that a minimum of two years is required before teachers adopt or become competent in using new practices (Martin \& Hand, 2009). Still other research has identified no immediate effect on student performance after professional development interventions (Allen et al., 2011; Osborne et al., 2013), or found no effect until the year after the intervention (Allen et al., 2011). From these perspectives, the results of this study are encouraging because the professional development was shown to be effective after only one year of the planned two-year program. Thus, the study has shown that student performance can be positively influenced by teachers' participation in professional development programs. This finding supports Clarke's and Hollingsworth's (2002) claims that teachers' professional growth in knowledge and in classroom practices can lead to improved student outcomes. It also aligns with their view of teacher professional growth as a series of changes in multiple domains that over time may lead to improved student outcomes rather than a linear pathway. Indeed, this complex and interconnected view of teacher professional growth supports the design of professional development programs over extended periods of time, to engage teachers in multiple opportunities for learning, implementation, experimentation, and reflection, as was the case in this study.

The study has some limitations, the first of which is the influence on the control class teachers by the participating teachers at their respective schools. This might be avoided by selecting control classes from like schools not involved in the professional development program. Secondly, it is unclear whether the impact of the professional development on students' learning outcomes may have been observed to a greater extent in the second year of the program. It was not possible to use the diagnostic instrument in the second year because there were too few students who continued in the second school year with the same teacher.

\section{Conclusion}

This study makes a valuable contribution to the limited literature on the effect of 
professional development on mathematics students' learning. It has shown that professional development that promotes teachers' conceptual knowledge and classroom strategies associated with proportional reasoning can impact on students' learning outcomes. The results indicate that learning gains occur across year levels and in a range of proportional and non-proportional situations but that the promotion of proportional reasoning takes considerable time and for many students, even with a targeted classroom focus, there is a need for further instruction and exposure to these important skills and concepts.

\section{Acknowledgements}

This research was funded by Australian Research Council, in partnership with Department of Education and Child Development SA and individual Education Queensland schools. 


\section{References}

Ahl, V. A., Moore, C. F., \& Dixon, J. A. (1992). Development of intuitive and numerical proportional reasoning. Cognitive Development, 7, 81-108.

Akatugba, A. H., \& Wallace, J. (2009). An integrative perspective on students' proportional reasoning in high school physics in a West African context. International Journal of Science Education, 31(11), 1473-1493.

Allen, J. P., Pianta, R. C., Gregory, A., Mikami, A. Y., \& Lun, J. (2011). An interaction-based approach to enhancing secondary school instruction and student achievement. Science, 333(6045), 1034-1037.

Barab, S., \& Squire, K. (2004). Design-based research: Putting a stake in the ground. Journal of the Learning Sciences, 13(1), 1-14.

Behr, M. J., Harel, G., Post, T., \& Lesh, R. (1992). Rational number, ratio, and proportion. In D. A. Grouws (Ed.), Handbook of research on mathematics teaching and learning (pp. 296333). New York: Macmillan

Ben-Chaim, D., Keret, Y., \& Ilany, B.-S. (2007). Designing and implementing authentic investigative proportional reasoning tasks: The impact on pre-service mathematics teachers' content and pedagogical knowledge and attitudes. Journal of Mathematics Teacher Education, 10, 333-340.

Boyer, T. W., \& Levine, S. C. (2012). Child proportional scaling: Is $1 / 3=2 / 6=3 / 9=4 / 12$ ? Journal of Experimental Child Psychology, 111, 516-533.

Boyer, T. W., Levine, S. C., \& Huttenlocher, J. (2008). Development of proportional reasoning: Where young children go wrong. Developmental Psychology, 44(5), 1478-1490.

Bright, G. W., Joyner, J. M., \& Wallis, C. (2003). Assessing proportional thinking. Mathematics Teaching in the Middle School, 9(3), 166-172.

Chandrasegaran, A. L., Treagust, D. F., \& Mocerino, M. (2008). An evaluation of a teaching intervention to promote students' ability to use multiple levels of representation when 
describing and explaining chemical reactions. Research in Science Education, 38, 237 248.

Clarke, D., \& Hollingsworth, H. (2002). Elaborating a model of teacher professional growth. Teaching and Teacher Education, 18, 947-967.

Cobb, P., Confrey, J., diSessa, A., Lehrer, R., \& Schauble, L. (2003). Design experiments in educational research. Educational Researcher, 32(1), 9-13.

Coenders, F. (2010). Teachers' professional growth during the development and class enactment of context-based chemistry student learning material. Enschede, The Netherlands: University of Twente. Retrieved from http://doc.utwente.nl/71370/1/thesis_F_Coenders.pdf

Cortina, J. L., Visnovska, J., \& Zuniga, C. (2014). Unit fractions in the context of proportionality: Supporting students' reasoning about the inverse order relationship. Mathematics Education Research Journal, 26, 79-99.

Cramer, K. M., \& Post, T. (1993). Connecting research to teaching proportional reasoning. Mathematics Teacher, 86(5), 404-407.

English, L. D., \& Halford, G. S. (1995). Mathematics education: Models and processes. Mahwah, NJ: Lawrence Erlbaum Associates.

Fielding-Wells, J., Dole, S., \& Makar, K. (2014). Inquiry pedagogy to promote emerging proportional reasoning in primary students. Mathematics Education Research Journal, $26,47-77$.

Goldsmith, L. T., Doerr, H. M., \& Lewis, C. C. (2014). Mathematics teachers' learning: A conceptual framework and synthesis of research. Journal of Mathematics Teacher Education, 17, 5-36.

Guskey, T. R. (1986). Staff development and the process of teacher change. Educational Researcher, 15(5), 5-12. 
Guskey, T. R. \& Yoon, K. S. (2009). What works in professional development. Phi Delta Kappan, 90(7), 495-500.

Halsam, F., \& Treagust, D. F. (1987). Diagnosing secondary students' misconceptions of photosynthesis and respiration in plants using a two-tier multiple choice instrument. Journal of Biological Education, 21, 203-211.

Hawley, W. D., \& Valli, L. (1999). The essentials of effective professional development: A new consensus. In L. Darling-Hammond \& G. Sykes (Eds.), Teaching as the learning profession: Handbook of policy and practice (pp. 127-150). San Francisco: Jossey-Bass Publishers.

Hiebert, J. S., \& Grouws, D. A. (2007). The effects of classroom mathematics teaching on students' learning. In F. K. Lester Jr. (Ed.), Second handbook of research on mathematics teaching and learning (pp. 371-404). Reston, VA: National Council of Teachers of Mathematics.

Hilton, A., Hilton, G., Dole, S., \& Goos, M. (2013). Development and application of a two-tier diagnostic instrument to assess middle years students' proportional reasoning. Mathematics Education Research Journal, 25, 523-545.

Howe, C., Nunes, T., \& Bryant, P. (2011). Rational number and proportional reasoning: Using intensive quantities to promote achievement in mathematics and science. International Journal of Science and Mathematics Education, 9, 391-417.

Ingvarson, L., Meiers, M. \& Beavis, A. (2005). Factors affecting the impact of professional development programs on teachers' knowledge, practice, student outcomes \& efficacy. Education Policy Analysis Archives, 13(10). Retrieved from http://epaa.asu.edu/epaa/v13n10/.

Jones, G., Taylor, A., \& Broadwell, B. (2009). Estimating Linear Size and Scale: Body rulers. International Journal of Science Education, 31(11), 1495-1509. 
Justi, R., \& Van Driel, J. (2006). The use of the Interconnected Model of Teacher Professional Growth for understanding the development of science teachers' knowledge on models and modelling. Teaching and Teacher Education, 22, 437-450.

Kastberg, S. E., D’Ambrosio, B., \& Lynch-Davis, K. (2012). Understanding proportional reasoning for teaching. Australian Mathematics Teacher, 68(3), 32-40.

Lamon, S. J. (2007). Rational numbers and proportional reasoning: Toward a theoretical framework for research. In F. K. Lester Jr. (Ed.), Second handbook of research on mathematics teaching and learning (pp. 629-668). Charlotte, NC: Information Age Publishing.

Lamon, S. J. (2005). Teaching fractions and ratios for understanding: Essential content knowledge and instructional strategies for teachers. Mahwah, NJ: Lawrence Erlbaum.

Lamon, S. J. (1993). Ratio and proportion: Connecting content and children's thinking. Journal for Research in Mathematics Education, 24(1), 41-61.

Langrall, C. W., \& Swafford, J. (2000). Three balloons for two dollars: Developing proportional reasoning. Mathematics Teaching in the Middle School, 6(4), 254-261.

Lesh, R., Post, T., \& Behr, M. (1988). Proportional reasoning. In J. Hiebert \& M. Behr (Eds.), Number concepts and operations in the middle grades (pp. 93-118). Reston, VA:

Lawrence Erlbaum \& National Council of Teachers of Mathematics.

Lo, J., \& Watanabe, T. (1997). Developing ratio and proportion schemes: A story of a fifth grader. Journal for Research in Mathematics Education, 28(2) 216-236

Lobato, J., Orrill, C. H., Druken, B., \& Jacobson, E. (2011). Middle school teachers' knowledge of proportional reasoning for teaching. Paper presented in the Symposium: Extending, expanding, and applying the construct of mathematical knowledge for teaching, at the Annual meeting of the American Educational Research Association (April 8-12) in New Orleans, USA.

Loucks-Horsley, S., Stiles, K. E., Mundry, S., Love, N., \& Hewson, P. W. (2010). Designing 
professional development for teachers of science and mathematics (3rd ed.). Thousand Oaks, CA: Corwin.

Luke, A., \& McArdle, R. (2009). A model for research-based state professional development policy. Asia-Pacific Journal of Teacher Education, 37(3), 231-251.

McKenney, S., \& Reeves, T. C. (2012). Conducting educational design research. Abingdon, UK: Routledge.

Mamlok-Naaman, R., \& Eilks, I. (2011). Different types of action research to promote chemistry teachers' professional development - A joined theoretical reflection on two cases from Israel and Germany. International Journal of Science and Mathematics Education, 2011, 1-30.

Martin, A. M., \& Hand, B. (2009). Factors affecting the implementation of argument in the elementary science classroom: A longitudinal case study. Research in Science Education, 39(17-38).

Misailidou, C., \& Williams, J. (2003). Diagnostic assessment of children's proportional reasoning. Journal of Mathematical Behavior, 22, 335-368.

Nabors, W. (2003). From fractions to proportional reasoning: A cognitive schemes of operation approach. Journal of Mathematical Behavior, 22, 133-179.

National Council of Teachers of Mathematics. (1989). Curriculum and evaluation, standards for school mathematics. Reston, VA: Author.

Osborne, J., Simon, S., Christodoulou, A., Howell-Richardson, C., \& Richardson, K. (2013). Learning to argue: A study of four schools and their attempt to develop the use of argumentation as a common instructional practice and its impact on students. Journal of Research in Science Teaching, 50(3), 315-347.

Özmen, H. (2008). The influence of computer-assisted instruction on students' conceptual understanding of chemical bonding and attitude toward chemistry: A case study for Turkey. Computers and Education, 51(1), 423-438. 
Reeves, T. C., McKenney, S., \& Herrington, J. (2011). Publishing and perishing: The critical importance of educational design research. Australasian Journal of Educational Technology, 27(1), 55-65.

Siebert, D. (2002). Connecting informal thinking and algorithms: The case of division of fractions. In B. Litwiller \& G. Bright (Eds.), Making sense of fractions, ratios, and proportions: 2002 Yearbook (pp. 247-256). Reston, VA: National Council of Teachers of Mathematics.

Siemon, D., Izard, J., Breed, M., \& Virgona, J. (2006). The derivation of a learning assessment framework for multiplicative thinking. In J. Novotná, H. Moraová, M. Krátká, \& N. Stehlíková (Eds.), Proceedings of the 30th Conference of the International Group for the Psychology of Mathematics Education, (pp. 5-113 - 5-120). Prague, Czech Republic: Charles University.

Sowder, J. (2007). The mathematical education and development of teachers. In F. K. Lester, Jr. (Ed.), Second handbook of research on mathematics teaching and learning (pp. 157223). Reston, VA: National Council of Mathematics Teachers.

Sowder, J., Armstrong, B., Lamon, S. J., Simon, M., Sowder, L., \& Thompson, A. (1998). Educating teachers to teach multiplicative structures in the middle grades. Journal of Mathematics Teacher Education, 1, 127-155.

Staples, M. E., \& Truxaw, M. P. (2012). An initial framework for the language of higher-order thinking mathematics practices. Mathematics Education Research Journal, 24(3), 257281.

Taber, S. B. (2002). Go ask Alice about multiplication of factions. In B. Litwiller \& G. Bright (Eds.), Making sense of fractions, ratios, and proportions: 2002 Yearbook (pp. 61-71). Reston, VA: National Council of Teachers of Mathematics.

Tan, K.-C. D. \& Treagust, D. F. (1999). Evaluating students' understanding of chemical bonding. School Science Review, 81(294), 75-83. 
Thompson, A. G., \& Thompson, P. W. (1996). Talking about rates conceptually, Part II:

Mathematical knowledge for teaching. Journal for Research in Mathematics Education, 27, 2-24.

Tourniaire, F., \& Pulos, S. (1985). Proportional reasoning: A review of the literature. Educational Studies in Mathematics, 16, 181-204.

Tsui, C.-Y. \& Treagust, D. F. (2009). Evaluating secondary students' scientific reasoning in genetics using a two-tier diagnostic instrument. International Journal of Science Education, 32(8), 1073-1098.

Tüysüz, C. (2009). Development of a two-tier diagnostic instrument to assess students' understanding in chemistry. Scientific Research and Essay, 4(6), 626-631.

Van De Walle, J. A., Karp, K. S., \& Bay-Williams, J. M. (2010). Elementary and middle school mathematics: Teaching developmentally. Boston, MA: Allyn \& Bacon.

Van Dooren, W., De Bock, D., Hessels, A., Janssens, D., \& Verschaffel, L. (2005). Not everything is proportional: Effects of age and problem type on propensities for overgeneralisation. Cognition and Instruction, 23(1), 57-86.

Van Dooren, W., De Bock, D., \& Verschaffel, L. (2010). From addition to multiplication ... and back: The development of students' additive and multiplicative reasoning skills. Cognition and Instruction, 28(3), 360-381.

Watson, J., \& Beswick, K. (2011). School pupil change associated with a continuing professional development programme for teachers. Journal of Education for Teaching, 37(1), 63-75.

Witterholt, M., Goedhart, M., Suhre, C., \& van Streun, A. (2012). The interconnected model of professional growth as a means to assess the development of a mathematics teacher. Teaching and Teacher Education, 28, 661-674. 